\title{
A Qualitative Study on the Process of the Mental Health Assessment and Intervention after the Sewol Ferry Disaster: Focusing on Survivors among Danwon High School Students
}

\author{
Mi-Sun Lee ${ }^{1}$, Jun-Won Hwang ${ }^{2}$, and Soo-Young Bhang ${ }^{3}$ \\ ${ }^{1}$ Department of Meditation Psychology, Nungin University, Hwaseong, Korea \\ 2Department of Psychiatry, Kangwon National University School of Medicine, Chuncheon, Korea \\ ${ }^{3}$ Department of Psychiatry, Eulji University School of Medicine, Eulji University Hospital, Seoul, Korea
}

\begin{abstract}
Objectives: This study aimed to identify the process of psychosocial assessment, the experience of intervention, and the improvement after the disaster that Danwon high school students survived from the sinking of the Motor Vessel (MV) Sewol in South Korea on April 16, 2014.

Methods: We conducted in-depth qualitative research using individual interviews from January to February 2017. Twenty-one of 75 Danwon high school students survived by the MV Sewol disaster were studied. Two interviewers participated in the in-depth interview. Interviews were transcribed verbatim, coded, and analyzed through content analysis based on psychosocial assessment and intervention after the disaster.

Results: Twenty-one participants were 20 years old, where 10 were male (47.62\%), and 11 were female (52.38\%). More than $75 \%$ of the interviewed students felt that mental health services were needed, and more than $85 \%$ required mental health assessments. Regarding psychiatric symptoms, the students reported that they suffered depression and insomnia (19.05\%), anxiety (14.29\%), nightmares and phobias (9.52\%), and difficulties regarding concentration, aggression, and game addiction (4.76\%).

Conclusion: Despite survivors experiencing the same disaster, there were differences in their responses to mental health assessments and interventions experienced during the three years, and conflicting opinions were reported. In planning future evaluations and interventions, it is necessary for strategies to cope with flexibly to consider the characteristics and symptoms of the survivors while maintaining principles.
\end{abstract}

Key Words: Mental health; Assessment; Intervention; Qualitative study; Sewol Ferry Disaster; Survivors.

Received: April 3, 2018 / Revision: June 27, 2018 / Accepted: August 13, 2018

Address for correspondence: Soo-Young Bhang, Department of Psychiatry, Eulji University School of Medicine, Eulji University Hospital, 68 Hangeulbiseok-ro, Nowon-gu, Seoul 01830, Korea

Tel: +82-2-970-8303, Fax: +82-2-970-8429, E-mail: bsy1@eulji.ac.kr

\section{INTRODUCTION}

Large-scale disasters and traumatic events cause distress in individuals that directly affect by them and their families and that severely affect the recovery and overall development of the traumatized children and adolescents [1]. Psychiatric symptoms in children and adolescents exposed to traumatic events show a wide variety of manifestations depending on their stage of development. In recent years, an increasing number of studies have examined the impact of disasters on the mental health of children and adolescents $[2,3]$,

This is an Open Access article distributed under the terms of the Creative Commons Attribution Non-Commercial License (https://creativecommons.org/licenses/by-nc/4.0) which permits unrestricted non-commercial use, distribution, and reproduction in any medium, provided the original work is properly cited. including reports on interventions undertaken to minimize the impact of disasters [4]. Such psychosocial problems should be efficiently managed and resolved through proactive interventions by local healthcare and disaster counseling professionals trained in the community [5].

Psychological First Aid (PFA) interventions are generally provided to children, adolescents, adults, and families in the immediate aftermath of disasters and terrorism [6]. "Project Liberty" provided PFA services in the aftermath of the terror attacks in New York City, USA, on September 11, $2001[7,8]$. Disaster Psychiatry Outreach, a non-profit voluntary organization of mental health specialists, provided 848 patients mental health services, such as mental health assessment, medication, PFA interventions, recommendations on con- 
tinuing treatments, and disaster response services, for two months after the 9/11 terror attacks [8]. In Japan, Mind Care Teams (心のケアチーム) were dispatched to the devastated regions in the aftermath of the 2011 Great East Japan Earthquake to perform counseling and medical services for children and adolescents to help them recover from the trauma, and the National Information Center of Disaster Mental Health was established to provide continuing psychological support and treatment for disaster victims [9].

In South Korea, the Sewol Ferry Disaster, where the passenger ferry Motor Vessel (MV) Sewol sunk, occurred on the morning of April 16, 2014, in the waters off Jindo, Jeollanam-do (near Gwanmae Island). Of the 476 passengers, 172 survived, with 299 confirmed dead and five missing. Of the 325 students of Danwon High School onboard MV Sewol on a field trip, only 75 (41 boys and 34 girls) survived the disaster. In the immediate aftermath of the Sewol Ferry Disaster, a range of mental health assessment and intervention services were offered to the surviving students. In a recent Korean study, analysis of questionnaires obtained from the 57 surviving students revealed that $26.3 \%$ showed clinical symptoms of post-traumatic stress disorder (PTSD) 20 months after the disaster [10]. Disaster-related studies have been carried out by a grant of the Korean Mental Health Technology R\&D Project, the Ministry of Health and Welfare, including cohort studies with individuals affected by the Sewol Ferry Disaster, including the survivors and bereaved families [11-13]. The U.S. National Child Traumatic Stress Network made offers PFA interventions for children and adolescents exposed to traumatic events in the acute phase and Skills for Psychological Recovery interventions in the subacute/chronic phase, followed by school-based continuing intervention programs. Given the difficulties in directly applying such principles and guidelines, which were established in a foreign country with a different cultural background from that of our situation, there is a need to establish important consideration points based on the experiences of the Sewol Ferry Disaster survivors for future applications to the related assessment and intervention services.

Against this background, we conducted in-depth interviews with the Sewol Ferry Disaster survivors regarding their experiences with mental health assessment and intervention practices, with a focus on the assessment and treatment of posttraumatic psychiatric disorders.

\section{METHODS}

\section{Subjects}

We recruited survey participants among the 75 Danwon High School students (11th grade), survivors of the Sewol
Ferry Disaster of April 16, 2014. We distributed an information sheet on the interviews and study in a mental health center in Ansan City for two months (November and December 2016), 31 months after the disaster. The information sheet contained information on the purpose of the research, participation period, number of research subjects, interview content, procedure, confidentiality, and so forth. The snowball sampling recruitment method was used to recruit additional participants through information sharing among the target students. Ultimately, 21 volunteers agreed to participate in the study and were given detailed information by email and individual phone calls. Additionally, we disclosed the research participants' rights and the researcher's obligations in that are customary in qualitative research. The face-toface in-depth interviews began after individually fine tuning the interview time, date, and venue.

\section{Assessment}

Since most of the participants preferred a venue close to their homes, the interviews were conducted in a counseling room of a mental health center in Ansan City. Two interviews conducted the in-depth interview, and each interview session lasted about $60 \mathrm{~min}$. The main interviewer (S.Y. Bhang), a child, and an adolescent psychiatrist administered the questionnaire items to the participant, and the secondary interviewer (M.S. Lee) was allowed to ask additional questions where deemed necessary. Each interview session was audio recorded, and the secondary interviewer recorded the observations made during the interview.

Drawing on our results of the studies $[14,15]$ conducted as a preliminary to this study, we set out guidelines for the questionnaire items in three major parts: 1) experience of mental health assessment by phase, 2) experience of mental health interventions and programs, and 3) experience-based suggestions in similar situations.

Based on the 2016 Research Report of the Special Investigative Committee Research Service for 4/16 Sewol Ferry Disaster [16], we divided the post-disaster period as follows: 1) first two weeks, which included the hyperacute phase in which most students were admitted to an Ansan-based university hospital (hereinafter the "university hospital"), 2) three to six weeks, which included the acute/subacute phase in which the students received group therapy in an training institute in Ansan City, 3) from the seventh week to the eleventh grade year ending in February (about eight months), which included the subacute/chronic phase in which mental health assessment and counseling programs were administered to the students in the school-based mental health center, consultation room (Wee Class), or the university hospital, 4) the twelfth grade year (one year starting from the 10th post-disaster 
month), which included the chronic phase in which students received continuing intervention programs in and out of school, and 5) from university entrance to the present (10 months starting from the 22nd post-disaster month), which included the chronic phase in which the school-based mental health center was closed and programs were offered by the Maumtodak Psychiatric Clinic, a psychiatric clinic and counseling center launched in Ansan City by the team of the former school-based mental health center, Ansan Mental Health Trauma Center created in the aftermath of the Sewol Ferry Disaster, and the Salvation Army in Korea, an international NGO (Fig. 1).

\section{Data analysis}

The main interviewer and secondary interviewer performed qualitative analysis based on the consolidated criteria for reporting qualitative research (COREQ) [17], one of the standard reporting guidelines available in the EQUATOR network's library. The COREQ guidelines represent the standard reporting form divided into three domains for the research team and reflexivity, study design, and analysis and findings, and they consist of 32 items of standard recommendations covering the aspects that should be included in a qualitative study, such as the composition of the research team participating in the analysis, theoretical framework, data collection and analysis process, data saturation, independent analysis, and external audit. After codifying the participants' names to protect their personal information, we generated verbatim transcripts of all the interviews. For analysis, all semantically related words were extracted from the interview contents and categorized into lower order cat-

Table 1. Demographic characteristics of the subjects $(n=21)$

\begin{tabular}{lc}
\hline \multicolumn{1}{c}{ Variables } & $\mathrm{N}(\%$ of details $)$ \\
\hline Age & $21(100.00)$ \\
20 years old & $10(47.62)$ \\
Gender & $11(52.38)$ \\
Male & \\
Female & $21(100.00)$ \\
Highest level of education & \\
High school graduate & $20(95.24)$ \\
Occupation & $1(4.76)$ \\
A first-year undergraduate & Public service worker
\end{tabular}

egories. Similar categories were then grouped into higher order categories. Analysis results were obtained after independent analysis by the two interviewers, subsequent discussion, an iterative process of adjusting the inconsistencies and reconstructing analysis details until all data relevant to topics, semantic units, and categories had been extracted and discussed. After a final check of the extracted contents and analysis results by the main interviewer, the two interviewers finalized the data categorization and determined the semantic structure of the interview contents. To ensure the validity of the study results, the finalized lower and higher order categories were reviewed by the co-author, who had not been directly involved in the interview process, and his opinions were reflected in the final formulation. No direct questions related to psychiatric pathology, which is beyond the scope of this study, were asked during the interviews. However, psychiatric symptoms were analyzed insofar as the interviewed survivors mentioned them as symptoms that they were suffering from or the interviewers could observe during the interview. The conduct of this study was approved by the Institutional Review Board of Eulji University, Eulji Hospital (IRB No. 2015-12-004).

\section{RESULTS}

\section{Sociodemographic characteristics}

In January/February 2017, 31 months after the Sewol Ferry Disaster, we performed face-to-face interviews [average duration: $52.86 \mathrm{~min}( \pm 7.86 \mathrm{~min})$ ] with 21 survivors [all aged 20 years old; 10 men (47.62\%), 11 women (52.38\%)]. All of them went to university, and one of them was in social service (alternative military service) (Table 1).

\section{Necessity of post-disaster mental health assessment}

The subjects' opinions on the post-disaster mental health assessment can be categorized into five types: 1) necessary and helpful because my feeling could be different from others ( $\mathrm{n}=6,28.57 \%), 2)$ partially necessary but not helpful because it did was not worth it for me $(\mathrm{n}=4,19.04 \%), 3)$ probably necessary but difficult to fill up ( $\mathrm{n}=5,23.81 \%), 4)$ not necessary for me but potentially helpful for someone $(n=3$, $14.29 \%), 5)$ refused because it was not necessary ( $n=3$, $14.29 \%)$.

Table 2. Needs of mental health service of the survivors ( $n=21$ )

\begin{tabular}{clccc}
\hline Type & Level of intervention needs & Total (\%) & Male (\%) & Female (\%) \\
\hline A & Need help for oneself & $10(47.62)$ & $5(23.81)$ & $5(23.81)$ \\
B & Not necessary for oneself, but someone might need help & $6(28.57)$ & $3(14.29)$ & $3(14.29)$ \\
C & Refuse to receive intervention & $5(23.81)$ & $2(9.52)$ & $3(14.29)$ \\
\hline
\end{tabular}




\section{Perceived demand for mental health intervention}

The subjects' opinions on the levels of their motivation for the mental health intervention were categorized into three types: Type A, "I need mental health care" ( $\mathrm{n}=10,(47.62 \%)$, Type B="I myself have no need for mental health care but others might need it" ( $n=6,28.57 \%)$, and Type $C$, "I refuse mental health care $(\mathrm{n}=5,23.81 \%)$ (Table 2).

\section{Preferences for mental health intervention}

As for the subjects' preferences for mental health intervention, we rated the degree of preference for the individual (1:1) or group interview, inactive or active intervention. The degree of preference was rated on a four-point scale: $\bigcirc$ : much preferred, $\bigcirc$ : preferred, $\triangle$ : neutral, and X: not preferred (Table 3). Four preference options were presented according to the individual vs. group interview and inactive vs. active intervention: 1) individual interview+inactive intervention, 2) individual interview+dynamic intervention, 3) group interview+inactive intervention, and (4) group interview+ dynamic intervention (Fig. 2).

\section{Experiences of mental health intervention by phase}

The first two weeks: hyperacute phase, hospitalized in the university hospital located in Ansan City

The subjects' experiences of mental health assessment in this period were divided into two higher order categories, namely, "difficulty of event recognition" and "unwillingness regarding questionnaire survey," conceptualized in five lower order categories (Supplementary Table 1 in the online-only Data Supplement).

We categorized their experiences of mental health intervention and hospital stay into six higher order categories of "refusal to participate in intervention programs," involuntary and unwitting participation," "awareness of others' eyes on patients," "helpful/positive aspects," "experiences of program activities," and "outings and visits without permission," conceptualized into 18 lower order categories (Supplementary Table 1 in the online-only Data Supplement).

The survivors remembered the difficulties that they had in recognizing the situation in the hyperacute phase, showing unwillingness toward mental health assessment $(n=19)$. They mostly preferred individual counseling with a face-to-face interview structure $(\mathrm{n}=17)$ and expressed discomfort with group counseling. About 52\% ( $\mathrm{n}=11)$ found the help offered during the hospital stay to ease them of their overwhelming emotional burden. Some of them $(n=4)$ practiced stabilization techniques with psychiatrists during the hospital stay. About $43 \%(n=9)$ found having group interactions in a safe and comfortable environment prepared in the hospital for the survivors, engaging in art activities, watching performances, and playing board games to be positive. Some complained

Table 3. Analysis of mental health service preference of the survivors $(n=21)$

\begin{tabular}{|c|c|c|c|c|c|c|c|c|c|}
\hline Subject & Gender & Individual & Group & Inactive & Active & $\|$ & $\mathrm{IA}$ & Gl & GA \\
\hline 1 & Female & (2) & 0 & $\sqrt{ }$ & & $\sqrt{ }$ & & & \\
\hline 2 & Male & O & $x$ & $\sqrt{ }$ & & $\sqrt{ }$ & & & \\
\hline 3 & Male & $\triangle$ & $\triangle$ & $\sqrt{ }$ & & $\sqrt{ }$ & & $\sqrt{ }$ & \\
\hline 4 & Female & O & (2) & & $\sqrt{ }$ & & & & $\sqrt{ }$ \\
\hline 5 & Female & $x$ & o & & $\sqrt{ }$ & & & & $\sqrt{ }$ \\
\hline 6 & Male & $x$ & 0 & & $\sqrt{ }$ & & & & $\sqrt{ }$ \\
\hline 7 & Male & O & $x$ & $\sqrt{ }$ & & $\sqrt{ }$ & & & \\
\hline 8 & Female & O & $x$ & & $\sqrt{ }$ & & $\sqrt{ }$ & & \\
\hline 9 & Female & O & $\triangle$ & & $\sqrt{ }$ & & $\sqrt{ }$ & & \\
\hline 10 & Female & (2) & O & & $\sqrt{ }$ & & $\sqrt{ }$ & & \\
\hline 11 & Male & O & $x$ & & $\sqrt{ }$ & & $\sqrt{ }$ & & \\
\hline 12 & Female & $x$ & O & & $\sqrt{ }$ & & & & $\sqrt{ }$ \\
\hline 13 & Female & $\triangle$ & O & & $\sqrt{ }$ & & & & $\sqrt{ }$ \\
\hline 14 & Male & O & $x$ & & $\sqrt{ }$ & & $\sqrt{ }$ & & \\
\hline 15 & Male & $x$ & $x$ & & $\sqrt{ }$ & & & & \\
\hline 16 & Female & o & (2) & $\sqrt{ }$ & & & & $\sqrt{ }$ & \\
\hline 17 & Male & o & $x$ & & $\sqrt{ }$ & & $\sqrt{ }$ & & \\
\hline 18 & Female & O & $x$ & $\sqrt{ }$ & & $\sqrt{ }$ & & & \\
\hline 19 & Male & O & $x$ & & $\sqrt{ }$ & & $\sqrt{ }$ & & \\
\hline 20 & Female & $x$ & $x$ & & $\sqrt{ }$ & & & & \\
\hline 21 & Male & o & $\triangle$ & $\sqrt{ }$ & & $\sqrt{ }$ & & & \\
\hline
\end{tabular}

GA: group-active, GI: group-inactive, IA: individual-active, II: individual-inactive 


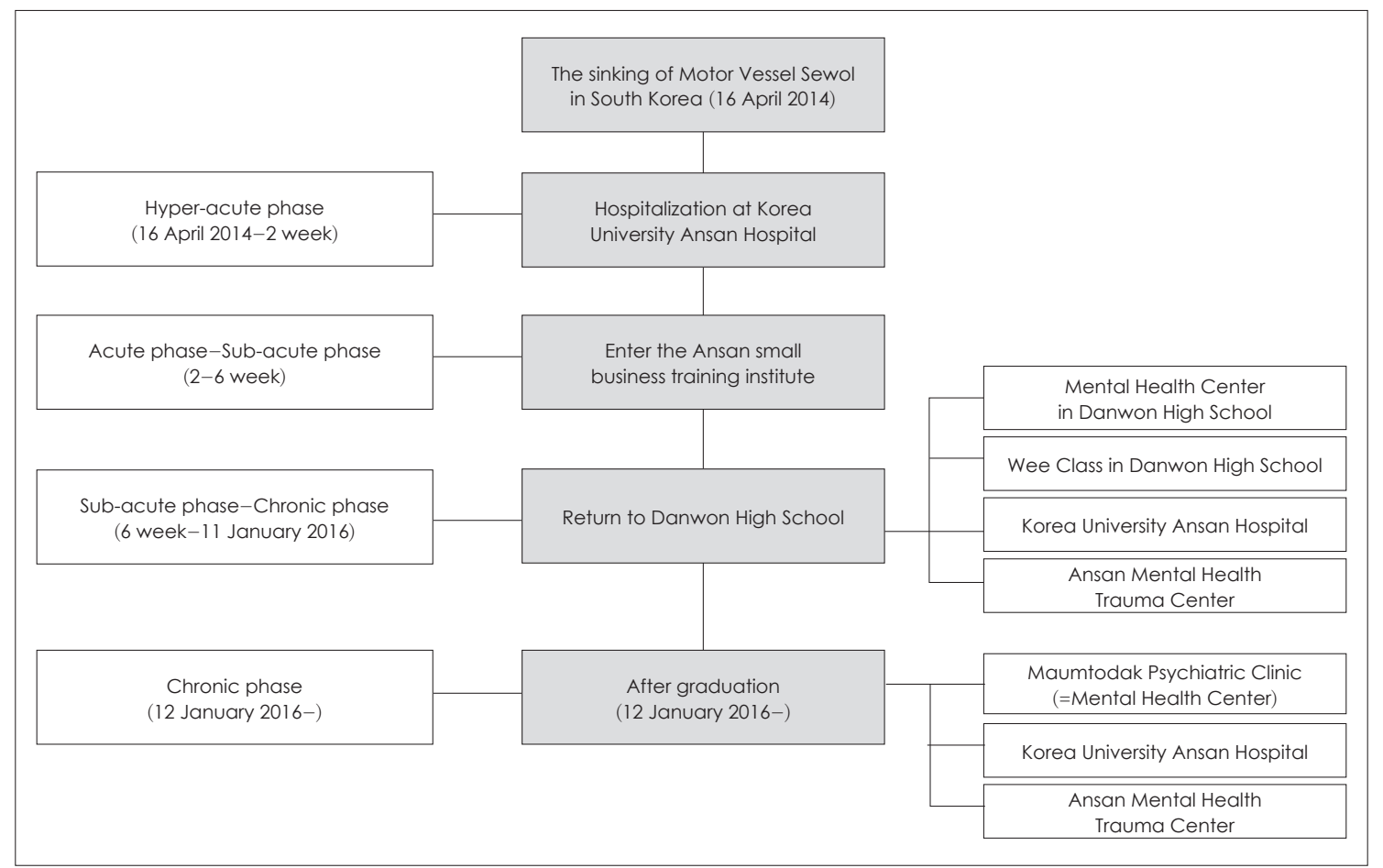

Fig. 1. Flowchart of psychological assessment and intervention for survivors in Danwon High School after the Sewol Ferry Disaster. Maumtodak Psychiatric Clinic was established personally by psychiatrists and psychologists who worked at the Mental Health Center in Danwon High School after 4.16 survivors had graduated.

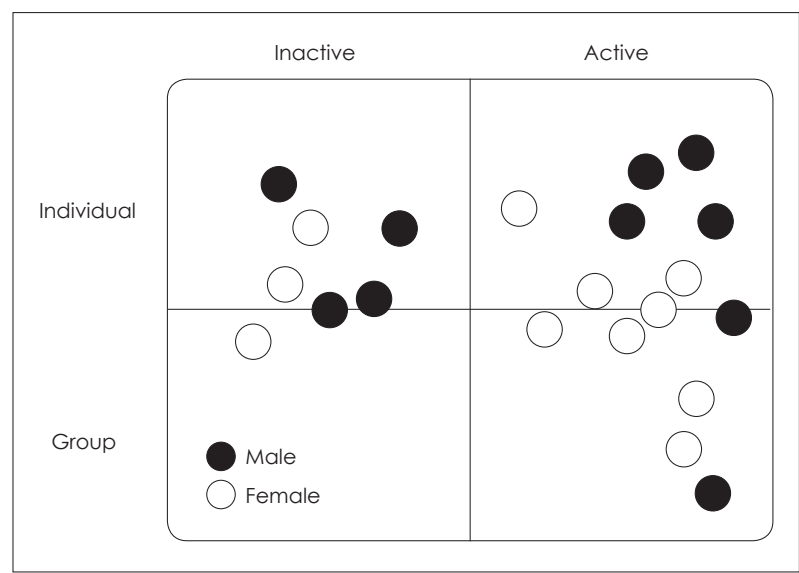

Fig. 2. Chart of the mental health service preference of survivors $(n=21)$.

(unasked) that they could not leave the hospital, not even to participate in their friends' funerals. Some obeyed and voluntarily stayed in hospital $(n=4)$, others sneaked out to the funerals $(n=5)$, and still others were forced to stay $(n=8)$.

Three to six weeks: This was the acute/subacute phase, where participants retreated in an training institute in Ansan City

The survivors were transferred immediately after hospital discharge to a boarding training institute. According to a pub- lished report, they were exposed to therapeutic, educational, and recreational intervention programs during the retreat [16]. None of the interviewees received mental health assessment during the retreat.

With regard to mental health interventions during the retreat period, we classified the interview contents into seven higher order categories ("synergy of being together," "homogeneity of a group," "positivity of group activities," "difficulties in adapting to a new environment," "participation in various programs," "negative perception of programs offered," "hope and preparation to return the daily life"), formulated in 25 lower order categories (Supplementary Table 2 in the online-only Data Supplement).

The earlier days of the training institute were an acclimation phase, and most of the surviving students found it difficult to participate in the group activities offered $(n=16)$. With days passing by, they expressed their dissatisfaction more frequently $(n=7)$. In addition to post-traumatic symptoms, they were faced with the task of rebuilding their comradeship ( $n=7)$. However, most of them found comfort in the fact that they could share their feelings and thoughts, living in the same space, as students of the same high school that went through the same experience $(n=15)$. In the mid- and late-phase of a training institute retreat, school classes were added to the daily activities to prepare them for a return to 
school. However, they found it difficult to concentrate on studies $(n=13)$. Moreover, most of them had to go regularly to the outpatient clinic of the university hospital for continuing counseling and care $(\mathrm{n}=19)$.

Regarding the counseling process, both positive and negative experiences were shared. They could pour their heart out to the designated counselor. They thought highly of the counselors who did their best to listen to their needs and interests $(n=6)$ and preferred those who treated them as any other students rather than patients $(n=4)$. On the other hand, they had negative opinions of the counselors who repeated the questions about their experiences of the event or asked them to imagine circumstances to recall their memories of the event or even compelled them to tell their stories to the public $(n=11)$. One of the programs with positive reports from most students ( $\mathrm{n}=15)$ was a self-initiated program in which a group game popular among the peers was presented by several teams with the rules set out by themselves. To sum up, the students reported a high level of satisfaction with the group life with peers in the hospital and camp $(n=12)$, but they also had deep longings to return to their daily lives $(n=4)$.

\section{From the seventh week to the eleventh-grade year end (about eight months): subacute/chronic phase, return to school}

A few days into the return to school, a school-based mental health center, consisting of one psychiatrist and two clinical psychologists, began its intervention programs. Additionally, the students could continue to receive counseling and care at the university hospital.

We analyzed the subjective experiences of the students about the mental health assessments administered in this period for both providers. Those administered by the schoolbased mental health center were classified into four higher level categories ("familiarity with questionnaire administration," "discomfort with questionnaire administration," "administration of various types of assessment," and "understanding of the assessment results") and seven lower level categories. Those administered by the university hospital were classified into two higher level categories (=lower level categories) of "regular assessments" and "memory of the assessment results (Supplementary Table 3 in the online-only Data Supplement).

Regarding the mental health interventions, three higher level categories ("formation of rapport with the counselor," "regular counseling schedule," and "positive perception of counseling") and 14 lower level categories could be extracted for the school-based mental health center, and three higher level categories ("relaxed counseling," "regret/frustration about counseling," and "consultation for medication") and nine lower level categories could be extracted for the university hospital. As miscellaneous items, we extracted three higher level categories ("participation in trips and programs," "efforts on school work," and "griefs") and six lower level categories.

Most interviewees had positive memories of the staff of the school-based mental center $(\mathrm{n}=18)$. The mental health center created an environment where a puppy was provided to accompany them as emotional support. Back to school, the students were provided with various psychological support programs and curricular and extracurricular activities, including trips, choirs, plays, and career guidance. Many of them continued to receive counseling at the outpatient clinic of the university hospital $(n=13)$, which was allowed during class hours $(n=9)$. Some students found it difficult to participate in the programs offered by the school $(n=7)$, and others answered that they enjoyed activities in which they were interested $(n=6)$. In particular, they showed greater interest in active programs than in inactive programs $(n=8)$.

Twelfth-grade year (one year starting from the 10th postdisaster month): chronic phase, continuing intervention programs in and out of school

We classified the mental health assessments administered by the school-based mental health center into two higher level categories ("improved perception of assessment" and "difficulty of assessment administration") and four lower level categories and those administered by the university hospital as one higher level (=lower level) category ("administration of questionnaire survey") (Supplementary Table 4 in the onlineonly Data Supplement).

The mental health interventions provided by the schoolbased mental health center can be classified into four higher level categories ("continuation of counseling," "decrease in the frequency of counseling," "provision of necessary information and activity opportunities," and "refusal of counseling") and eight lower level categories. Those provided by the Ansan Mental Health Trauma Center were classified into one higher level category ("experience of various programs") and four lower level categories. Those provided by the university hospital were classified into four higher level categories ("regular outpatient care," "end of treatment," "refusal of in-depth care," and "refusal of outpatient care") and six lower level categories. We analyzed the remaining interview contents in four higher level categories ("difficulties with school work," "the first memorial ceremony," "hard preparations for university entrance exam," and "gratitude for helps received") and seven lower level categories.

This period corresponds to the chronic phase, and the majority opinion was that there was little difference between the mental health assessments and interventions they received 
the year before $(\mathrm{n}=16)$. Some said that they became with familiar with the questionnaire administration $(\mathrm{n}=5)$, whereas a few others still found it difficult to go through the assessment $(n=3)$. The school-based mental health center provided medication education and career guidance, and the Ansan Mental Health Trauma Center provided various learning programs, such as scented candle making and makeup classes. On April 16, 2015, the students prepared and participated in the first memorial ceremony, and a few students experienced psychiatric symptoms such as depression $(n=2)$. This period was packed with activities typical of all high school seniors (12th graders) in South Korea preparing for the university entrance exam, i.e., obtaining necessary knowledge and information, such as focused learning, career guidance meetings, presentation letter writing training, and mock interview training.

\section{After university entrance (10 months starting from} the 22nd post-disaster month): from graduation to immediately before the in-depth interview of this study

The school-based mental health center was closed, and its staff opened a Maumtodak Psychiatric Clinic in Ansan City. The programs offered by this clinic were classified into two higher level categories ("continuous assessment" and "increased willingness for assessment") and three lower level categories. Those offered by the Ansan Mental Health Trauma Center (Onmaum Center), which was created in the aftermath of the Sewol Ferry Disaster, were classified in the single higher/lower level category "no assessment" (Supplementary Table 5 in the online-only Data Supplement).

The mental health interventions were analyzed in two higher level categories ("experience of continuous counseling" and "concerns about symptoms") and four lower level categories. Those provided by the Ansan Mental Health Trauma Center were extracted as three higher level categories ("positive memories of the trip," "meetings with the counselor," and "no communication with the center") and eight lower level categories. The programs offered by the international
NGO Salvation Army can be classified into three higher level categories ("tutoring program," "joint activities," and "decision about future participation") and seven lower level categories. As miscellaneous items, we extracted four higher level categories ("continuous outpatient care," "burden of medical bills," "psychiatric medication," and "sense of responsibility and independence") and five lower level categories. Experience of university life was analyzed in two higher level categories ("initial adaptation difficulties" and "familiarity with university life") and nine lower level categories.

After graduation, most subjects continued their follow-up visits for mental health assessment every six months $(\mathrm{n}=14)$. By contrast, some of them continued the counseling provided by the former school doctors at the Maumtodak Psychiatric Clinic $(n=4)$, and many students rarely went to counseling, as they were busy with university life $(\mathrm{n}=7)$. Considering the subjects' voluntary reports, six of them (28.6\%) were most obviously in need of treatment even without a diagnostic interview. Many students were hesitant to visit the outpatient clinic due to the financial burden after the discontinuation of medical cost subsidies simultaneously with graduation $(n=9)$. About half of the students had great concerns about adapting to the new environment in the earlier months into university life $(\mathrm{n}=11)$. Some of them felt uneasy and embarrassed when asked during new student orientation about their high school $(\mathrm{n}=3)$, and some students were also under psychiatric care due to exacerbated anxiety and stress symptoms after beginning university $(\mathrm{n}=2)$. Some extreme cases were missed most lectures $(n=2)$, only stayed at home $(n=1)$, or had difficulties in learning $(\mathrm{n}=3)$.

Regarding mental health assessment, some subjects found such assessment positive as an opportunity to look into their own situation $(\mathrm{n}=7)$ or to understand their current situation through the questionnaire items $(n=5)$. However, most of them expressed strong negative feeling about the questionnaires, primarily due to the numerous items $(n=19)$. Some voiced the opinion that it would be better to administer a questionnaire survey selectively to those assessed necessary

Table 4. Analysis of observable psychiatric symptoms during the in-depth interview* $(n=21)$

\begin{tabular}{|c|c|c|c|}
\hline Variables & Total (\%) & Male (\%) & Female (\%) \\
\hline Depressive mood & $4(19.05)$ & $1(4.76)$ & $3(14.29)$ \\
\hline Anxiety & $3(14.29)$ & $2(9.52)$ & $1(4.76)$ \\
\hline Insomnia & $4(19.05)$ & $2(9.52)$ & $2(9.52)$ \\
\hline Nightmare & $2(9.52)$ & $2(9.52)$ & $0(0.00)$ \\
\hline Difficulty of concentration & $1(4.76)$ & $1(4.76)$ & $0(0.00)$ \\
\hline Phobia & $2(9.52)$ & $1(4.76)$ & $1(4.76)$ \\
\hline Aggression & $1(4.76)$ & $1(4.76)$ & $0(0.00)$ \\
\hline Game addiction & $1(4.76)$ & $1(4.76)$ & $0(0.00)$ \\
\hline
\end{tabular}

*multiple response items; grade response percentages are based on the total sample 
$(\mathrm{n}=6)$. As an appropriate interval of mental health assessments, once every six months was the majority opinion $(n=14)$. Regarding the duration of assessment, some opined that it may continue as long as they feel the need $(n=5)$.

\section{Psychiatric symptoms reported during the interviews}

The psychiatric symptoms reported by the subjects during the interview included depression, anxiety, insomnia, nightmares, poor concentration, phobia, aggression, and game addiction. The most frequent symptoms were depression and insomnia (19.05\% each), followed by anxiety (14.29\%), nightmares and phobia ( $9.52 \%$ each), poor concentration, aggression, and game addiction (4.76\% each) (Table 4 ).

\section{DISCUSSION}

Child and adolescent post-disaster mental health assessment mitigates such individuals' psychological vulnerability and promotes their recovery, thus playing a pivotal role in treatment and prognosis [18]. It is of crucial importance to administer mental health assessment to children and adolescents in order to manifest temporary stress responses immediately after exposure to traumatic events in order to ensure timely detection of a high-risk group for psychiatric disorders [19]. In doing so, however, it should be kept in mind that mental health assessment administered immediately after a disaster may cause negative changes to the survivors' psychological symptoms [20].

Over $75 \%$ of the students interviewed felt the need for mental health care, and over $85 \%$ found that the assessment was necessary. Many students reported (unasked) on the psychiatric symptoms that they were suffering from, such as depression (19.05\%), insomnia (19.05\%), anxiety (14.29\%), nightmare (9.52\%), and phobia (9.52\%), but some of them discontinued outpatient care due to the burden of hospital bills $(\mathrm{n}=3)$.

Considering most students' criticism that the questionnaire administered shortly after the disaster contained too many items, it is recommended to limit the number of items in the acute phase mental health assessment questionnaire. In-depth assessment can be administered if the survivors themselves agree, but an overly comprehensive assessment procedure without accounting for their conditions can be detrimental to developing a therapeutic rapport for continuing care. Regarding post-disaster assessment, Pfefferbaum and North [21] also recommend prior screening and subsequent in-depth assessment based on the screening results.

During the subacute phase, i.e., up to the second post-disaster month during which the survivors lived together in the retreat center, none of the interviewees had the experience of mental health assessment. This is the time point where
PTSD can be diagnosed, and it is hence important to screen potential PTSD patients. The control tower for psychological support has to establish a systematic care plan and implement it consistently. At that time, the National Center for Mental Health, Ansan Mental Health Trauma Center, and a university hospital in Ansan City were involved, but the control tower was rather chaotic [22]. The National Center for Trauma has now taken over the role of the control tower [23] along with five local branches of the National Center for Mental Health [24]. However, given the necessity for meeting the demands of local communities and establishing a separate system for children and adolescents, future research must address these unmet needs. Indeed, children and adolescents respond to trauma and loss in many different ways, showing widely varying ability in term of disaster experience, coping with emotional crises, preparedness [25], cautiousness, and personalized approaches.

Analysis of the in-depth interviews revealed the importance of rebuilding the comradeship among the survivors in relation to their mental health $(n=7,30 \%)$. Trauma care is of primordial importance, but rebuilding peer relationships also represents an important role. The surviving students also had opportunities to receive the support necessary for adapting to tasks pertaining to each school year through counseling related to the university entrance process or mentoring program after entering university $(\mathrm{n}=11,52 \%)$. It is thus important to properly identify and meet such needs in post-disaster situations under the involvement of a professional advisory organization in order to establish a relevant masterplan and implement it. In the acute phase immediately after an disaster, in particular, it is essential to collect information about the survivor's needs/wishes and concerns [26]. Based on the information collected in the acute phase, PFA can be provided in a flexible manner, and the priorities of mental health assessments and interventions can be set [27]. In cases in which disaster survivors witness injuries or losses of loved ones, a medical professional or institution that plans mental health assessments and treatments must consider their psychological pains and feelings of helplessness, especially while accounting from concerns about separation and safety. Moreover, in addition to obtaining information on survivors' medical history, previous trauma experience, and psychological problems, particular attention should be given to detect signs of guilt or shame [28].

According to the analysis results, preferences for intervention approaches were different among the students interviewed. In general, students preferred individual counseling to group counseling regarding psychologic symptoms. In the acute phase, in particular, most of them preferred faceto-face individual counseling ( $\mathrm{n}=17)$ and felt discomfort with 
group counseling $(\mathrm{n}=15)$. This implies that group counseling was not of much help in the hyperacute phase, where the survivors were overwhelmed by the symptoms. When trauma care begins before the responses to sorrow calm down, PTSD symptoms can be exacerbated [29]. Therefore, intervention should begin when each survivor is sufficiently prepared depending on the individual severity of symptoms and the level of psychological development. On this note, continuous knowledge and skill training of dedicated professionals is of vital importance so that they can provide timely and appropriate trauma care in constant preparedness [19].

In contrast with their preference for individual counseling regarding symptoms, the students were highly motivated to participate in physically demanding active programs $(66.7 \%, \mathrm{n}=14)$, prioritizing active over inactive intervention. This result supports the report of a previous study that intervention with physical activity, such as play and artistic activities, eases children and adolescents with suppressed emotions and fears coming from tension, anxiety, confusion, and the like, and boosts their open mindedness [30].

The participants in this study expressed their discomfort about having to repeat their stories in the hyperacute phase whenever there is a new therapist, where there is a difficulty in building therapeutic rapport and an exacerbation of PTSD symptoms, such as flashbacks and anxiety $(n=4)$. In the light of students' report that the continuous counseling with the same doctor of the school mental health center improved the therapeutic rapport and contributed to their feeling of stability $(n=10)$, the success of counseling cannot be expected from a one-time encounter, but it can be ensured only when good therapeutic rapport is established. In this context, it should be welcomed that the staff of the former schoolbased mental health center opened a private clinic so that the therapeutic rapport can be maintained. In addition, the Ansan Mental Health Trauma Center still offers various programs to their students, and this unbroken provider-beneficiary relationship throughout the students' school years and thereafter is very positive with respect to consistency.

In post-disaster situations, psychological recovery should be ensured by providing survivors with physical and emotional comfort and strengthening the feeling of safety [20], and doing so is crucial for maintaining counseling with the same therapist. Children and adolescents exposed to trauma should be provided with all necessary care, including psychological education, trauma-centered care, and counseling, right from the outset $[31,32]$. As exemplified by Project Liberty, an intervention project offered in the aftermath of the U.S. 9/11 terror attacks, taking into account the resources of the local community, individual, group, and family care for traumatized children and adolescents can be given in the local community, schools, and universities [33]. The time to recovery from trauma-related symptoms varies from person to person, and cases of long-standing symptoms are not rare $[34,35]$. Therefore, a policy ensuring continuous personalized care is required.

Grief is an essential point of consideration in the process of trauma care accompanied by losses [36]. Grief over the loss of loved ones is a normal process for coping with the feeling of loss, and it should be expedited appropriately [29]. According to the reports of the students interviewed in this study, they were not allowed to participate in the funerals of their friends against the opinions of medical staff and guardians, which were prioritized over their own [37], and more than $50 \%$ did not obey the ban $(n=13)$. Considering that they were going through a period in which they needed assistance to overcome the grief and build new peer relationships, sufficient considerations should have been made to understand the process of grief and help them overcome their grief while minimizing predictable risks.

The event remembered by many as the most positive experience during the time that they lived in the training institution was a group program that they planned and prepared themselves $(n=8)$, whereas the programs imposed on them according to the schedule were criticized as being unilateral $(\mathrm{n}=6)$. They remembered that they were hospitalized, lived together, and had to follow most of the activities as prescribed. Programs provided by the unilateral decision will likely meet with resistance of adolescents who attach importance to the right of self-determination. Even when they are not in a position to decide for themselves, it is important to make efforts to persuade them with sufficient explanations about the situation so that they are faced with unilateral notification. It is necessary to respect their autonomy by, for example, presenting a list of intervention programs and giving them options for voluntary participation. Recommended optional programs include talking to another person for support or spending time with others, getting adequate rest and ensuring healthy eating habits, engaging in positive distracting activities (sports, hobbies, reading) scheduling pleasant activities, trying to maintain a normal schedule, and participating in support groups [20].

During the interview, some students expressed gratitude to the volunteers and organizations that provided active support to the survivors and their families $(n=3)$. Social solidarity and support are presented in many forms, including emotional support, social relation building, the necessity for value attachment, self-confidence, trust, advice, physical assistance, and material support. Such initiatives also offer benefits of solving real problems and sharing information on emotional understanding, acceptance, experience, and prepared- 
ness [38]. It is an urgent task for the future to establish a social network with chains starting from pre-disaster situations so that a supportive social environment prepared for any crises can be created.

As limitations of this study, the following can be noted. Only 21 (28.0\%) of 75 surviving students participated in the study. Since the subjects are not a sample representing the population, the study results may be marred by a selection bias. Additionally, no comparison of characteristics could be made between the participants and non-participants among the surviving students due to the inaccessibility of the data on students who did not agree to participate. Given the nature of the study based on interviews about survivors' experiences 31 months after the Sewol Ferry Disaster, recall bias cannot be ruled out. Moreover, it is necessary to conduct a long-term follow-up study.

\section{CONCLUSION}

Analysis of the interview contents demonstrated different reactions of the Sewol Ferry Disaster survivors to the mental health assessments and interventions despite having the same disaster experience. The results of this study show the necessity of taking a comprehensive approach in account for subjects' characteristics, level of psychological development, prior experience of trauma, and the like. Over $75 \%$ of the students interviewed recognized the necessity of mental health care and admitted that they were still suffering from psychiatric symptoms almost three years after the disaster, demonstrating the need to identify and provide appropriate care. Survivors will have to be provided with consistent and continuous intervention programs, and a social solidarity network will have to be established to ensure safety, to promote psychological recovery, and to provide necessary resources. Other aspects, such as cultural sensitivity, government subsidies, and socio-economic factors, will also have to be considered to provide comprehensive assistance. The results of this study are expected to serve as useful data for setting up and implementing efficient mental health assessment and treatment strategies for traumatized children and adolescents.

\section{Supplementary Materials}

The online-only Data Supplement is available with this article at https://doi.org/10.5765/jkacap.180013.

\section{Acknowledgments}

This study was supported by a grant of the Korean Mental Health Technology R\&D Project, Ministry of Health \& Welfare, Republic of Korea (HM15C1058).

\section{Conflicts of Interest}

The authors have no financial conflicts of interest.

\section{REFERENCES}

1) Davidson JR, McFarlane AC. The extent and impact of mental health problems after disaster. J Clin Psychiatry 2006;67 Suppl 2: 9-14.

2) Vernberg EM, Hambrick EP, Cho B, Hendrickson ML. Positive psychology and disaster mental health: strategies for working with children and adolescents. J Clin Psychol 2016;72:1333-1347.

3) Kar N. Psychological impact of disasters on children: review of assessment and interventions. World J Pediatr 2009;5:5-11.

4) Gard BA, Ruzek JI. Community mental health response to crisis. J Clin Psychol 2006;62:1029-1041.

5) Somasundaram DJ, van de Put WA. Management of trauma in special populations after a disaster. J Clin Psychiatry 2006;67 Suppl 2: 64-73.

6) Shultz JM, Forbes D. Psychological first aid: rapid proliferation and the search for evidence. Disaster Health 2014;2:3-12.

7) Stuber J, Fairbrother G, Galea S, Pfefferbaum B, Wilson-Genderson M, Vlahov D. Determinants of counseling for children in Manhattan after the September 11 attacks. Psychiatr Serv 2002;53:815822.

8) Pandya A, Katz CL, Smith R, Ng AT, Tafoya M, Holmes A, et al. Services provided by volunteer psychiatrists after $9 / 11$ at the New York City family assistance center: September 12-November 20, 2001. J Psychiatr Pract 2010;16:193-199.

9) Oh MA, Paik JW, Na KS, Kim NR, Chung CS, Lee HK, et al. Review of disaster mental health system in Japan. J Korean Neuropsychiatr Assoc 2015;54:6-10.

10) Lee SH, Kim EJ, Noh JW, Chae JH. Factors associated with posttraumatic stress symptoms in students who survived 20 months after the Sewol ferry disaster in Korea. J Korean Med Sci 2018;33:e90.

11) Huh HJ, Huh S, Lee SH, Chae JH. Unresolved bereavement and other mental health problems in parents of the Sewol ferry accident after 18 months. Psychiatry Investig 2017;14:231-239.

12) Lee SH, Nam HS, Kim HB, Kim EJ, Won SD, Chae JH. Social support as a mediator of posttraumatic embitterment and perceptions of meaning in life among Danwon survivors of the Sewol ferry disaster. Yonsei Med J 2017;58:1211-1215.

13) Kim EJ, Nam HS, Kim HB, Chung U, Lee SH, Chae JH. A retrospective and prospective follow-up study of psychological distress in the Danwon high school survivors of the Sewol ferry disaster. Psychiatry Investig 2018;15:261-265.

14) Park JH, Lee MS, Chang HY, Hwang JW, Lee JH, Kim JY, et al. The major elements of psychological assessment and intervention for children and adolescents after a disaster: a professional Delphi preliminary survey. J Korean Acad Child Adolesc Psychiatry 2016; 27:164-172.

15) Lee MS, Hwang JW, Lee CS, Kim JY, Lee JH, Kim E, et al. Development of post-disaster psychosocial evaluation and intervention for children: results of a South Korean delphi panel survey. PLoS One 2018;13:e0195235.

16) 4.16 Special Investigative Committee. A survey on survivors of Danwon high school students South Korea: Research report of the Special Investigative Committee Research Service for 416 Sewol Ferry Disaster. Seoul: Yurim;2016.

17) Tong A, Sainsbury P, Craig J. Consolidated criteria for reporting qualitative research (COREQ): a 32-item checklist for interviews and focus groups. Int J Qual Health Care 2007;19:349-357.

18) Witt PH, Greenfield DP, Steinberg J. Evaluation and treatment of post-traumatic stress disorder. N J Med 1993;90:464-467.

19) Bryant RA. Recovery after the tsunami: timeline for rehabilitation. J Clin Psychiatry 2006;67 Suppl 2:50-55. 
20) Pekevski J. First responders and psychological first aid. J Emerg Manag 2013;11:39-48.

21) Pfefferbaum B, North CS. Child disaster mental health services: a review of the system of care, assessment approaches, and evidence base for intervention. Curr Psychiatry Rep 2016;18:5.

22) Chae JH. Clinician's corner: mental health response to the Sewo ferry passenger ship sunk in South Korea. International Society for Traumatic Stress Studies [serial online] 2015 Dec 18 [cited 2017 Sep 12]. Available from: http://www.istss.org/education-research/ traumatic-stresspoints/2015-december/clinician-s-corner-mentalhealth-response-to-the-s.aspx.

23) Yonhap News. Gov't opens trauma center for disaster victims. Yonhap news agency. [serial online] 2018 Apr 4 [cited 2018 Jun 13] Available from URL:http://english.yonhapnews.co.kr/search1/2603000000. html?cid=AEN20180404007200320.

24) Paik JW, Kim HS, Sim MY, Lee HK, Woo YS, Chung CS, et al. The Sewol ferry accident and early mental health care response by volunteer activities of Korean disaster mental health committee and members of Korean neuropsychiatric association. J Korean Neuropsychiatr Assoc 2015;54:1-5.

25) NCTSN. Early childhood trauma. The national child traumatic stress network. [serial online] 2010 Aug 23 [cited 2018 Mar 27] Availiable from URL:https://www.nctsn.org/what-is-child-trauma/trauma-types/early-childhood-trauma.

26) American Psychological Association. Clinical practice guideline for the treatment of PTSD in adults. Washington, DC: American Psychological Association;2017.

27) McCabe OL, Everly GS Jr, Brown LM, Wendelboe AM, Abd Hamid NH, Tallchief VL, et al. Psychological first aid: a consensus-derived, empirically supported, competency-based training model. Am J Public Health 2014;104:621-628.
28) McMillan I. Psychological first aid. Nurs Times 1995;91:16.

29) Boelen PA, van den Bout J, van den Hout MA. The role of negative interpretations of grief reactions in emotional problems after bereavement. J Behav Ther Exp Psychiatry 2003;34:225-238.

30) Jafari N, Mohammadi MR, Khanbani M, Farid S, Chiti P. Effect of play therapy on behavioral problems of maladjusted preschool children. Iran J Psychiatry 2011;6:37-42.

31) APA Presidential Task Force on Evidence-Based Practice. Evidence-based practice in psychology. Am Psychol 2006;61:271-285.

32) Millegan J, Delaney EM, Klam W. Responding to trauma at sea: a case study in psychological first aid, unique occupational stressors, and resiliency self-care. Mil Med 2016;181:e1692-e1695.

33) Macy RD, Macy DJ, Gross S, Brighton P. Save the children basic training for the 9-session CBI: a psychosocial trauma informed structured intervention for youth facing life threat and other extreme traumatic stress exposures. Boston: Center for Trauma Psychology; 1999.

34) Neria $Y$, Olfson $M$, Gameroff $M J$, DiGrande L, Wickramaratne $P$, Gross R, et al. Long-term course of probable PTSD after the 9/11 attacks: a study in urban primary care. J Trauma Stress 2010;23:474482.

35) Tosone C, McTighe JP, Bauwens J, Naturale A. Shared traumatic stress and the long-term impact of 9/11 on Manhattan clinicians. J Trauma Stress 2011;24:546-552.

36) Jacobs S, Mazure C, Prigerson H. Diagnostic criteria for traumatic grief. Death Stud 2000;24:185-199.

37) Lee YG. Korea University Ansan hospital "Survivors of students do not want to be discharged from the hospital individually". The Asia Business Daily 2014 Apr 25.

38) Wynn ST. Natural disasters: planning for psychological first aid. J Christ Nurs 2017;34:24-28. 